\title{
Urdimento
}

Revista de Estudos em Artes Cênicas

E-ISSN: 2358.6958

\section{Em torno do performativo}

Entrevista com Josette Féral concedida à Edélcio Mostaço

\section{Para citar este artigo:}

FÉRAL, Josette. Em torno do performativo. Entrevista concedida à Edélcio Mostaço. Urdimento, Florianópolis, v. 2, n. 38, ago./set. 2020.

DOI: http:/dx.doi.org/10.5965/14145731023820200049 
Em torno do performativo

Josette Féral entrevista concedida à Edélcio Mostaço1

\title{
Resumo
}

Entrevista com Josette Féral realizada em setembro de 2019 na cidade de Lisboa, sede da conferência anual da EASTAP. Nela, a entrevistada discorre sobre as várias acepções de performativo, indica o que a seduz na cena e o que há de significativo no campo da teoria teatral contemporânea.

Palavras-chave: Josette Féral. Performativo. Teoria teatral.

\section{Around the performative}

\begin{abstract}
Interview with Josette Féral held in September 2019 in the city of Lisbon, host of the annual EASTAP conference. In it, the interviewee discusses the various meanings of the performative, indicates what seduces her on the scene and what is significant in the field of contemporary theatrical theory.
\end{abstract}

Keywords: Josette Féral. Performative. Theatrical theory. 


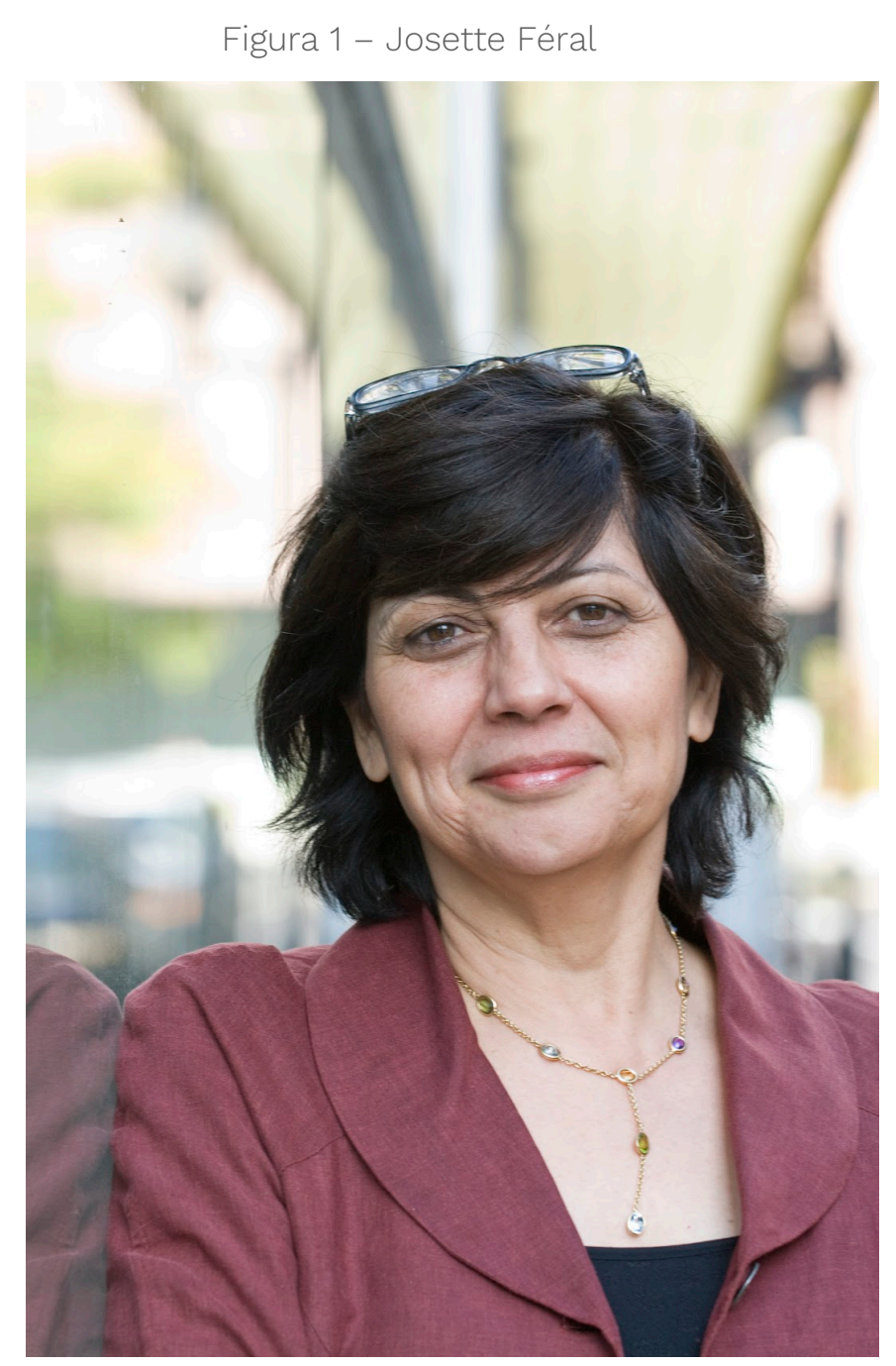

Fonte: https://professeurs.uqam.ca/professeur/feral.josette/

\section{Apresentação}

Em meio aos inúmeros compromissos de um congresso e também porque ela faz questão de estar presente a todas as mesas ali realizadas, consigo puxá-la pelo braço para uma breve conversa em torno de um café. Há anos não nos vemos, mas ela mantém a mesma simpatia e o mesmo sorriso jovial de sempre. Falamos sobre diversos temas, mas fiz aqui um recorte de assuntos, compatíveis com essa publicação.

Canadense de origem, Josette Féral concluiu seu doutorado na Sorbonne- 
Nouvelle, em Paris, em 1978, sob orientação de Julia Kristeva. Desde 1981 tornouse professora da Escola Superior de Teatro da UQUAM (Montreal). Sua primeira publicação de impacto em coautoria ocorreu em 1985, denominada Teatralidade, escritura e encenação (Hurtubise, $\mathrm{HMH}$, Collection Brèche), marcando um dos grandes temas que ela jamais abandonou. Trajetórias do Soleil (Editions théâtrales, 1998) e Vestir um monumento ao efêmero (Montréal, XYZ, 1995), constituíram dois importantes títulos dedicados a Ariane Mnouchkine e seu grupo que a consagraram como pesquisadora.

O que a levou a ser vice presidente e, a seguir, à presidência da FIRT (Fédération internationale pour la recherche théâtrale) entre 1999 e 2003. Essa destacada trajetória acadêmica se enriqueceu, a seguir, com a publicação de inúmeros títulos na área da teoria teatral, conduzindo-a, a seguir, a ocupar a vaga deixada por Georges Banu e tornar-se Professora Titular na Sorbonne-Nouvelle 3, Paris, em 2011, de onde se aposentou como Professora Emérita no ano passado. Desde o final da década de 1990, os interesses de pesquisa de Josette Féral voltaram-se para o estudo da performance - mais especificamente sobre o performativo -, o que se traduziu em uma polêmica com o estudioso alemão Hans-Thies Lehmann, criador do termo pós-dramático.

Reunindo uma expressiva quantidade de artistas, professores e pesquisadores de toda a Europa ela fundou, em 2017, a EASTAP (Associação Europeia para o Estudo do Teatro e da Performance), entidade que preside atualmente. O segundo congresso da associação, ocorrido em Lisboa em 2019, versou sobre o entrelaçamento entre memória, documentos e monumentos, alicerçando investigações de grande alcance teórico e prático.

Apenas dois livros de Josette Féral foram editados no Brasil: Encontros com Ariane Mnouchkine (SESC/SENAC, 2010) e Além dos Limites (Perspectiva, 2015) são as publicações disponíveis em português. Nessa última, contudo, um amplo panorama de seu trabalho intelectual pode ser encontrado, abrangendo enorme quantidade de vetores, temas, motivações e objetos de estudos. 


\section{Josette, o que é exatamente a EASTAP?}

É uma associação criada em outubro de 2017 que almeja reunir e agrupar pesquisadores e artistas em tono de questões teóricas e práticas inerentes ao teatro e à performance. O objetivo é também de nos centrarmos sobre a Europa, daí o nome de European Assotiation for The Study of Theatre and Performance (Associação Europeia de Estudos do Teatro e da Performance). A associação é europeia, porque está situada na Europa e porque reflete sobre questões europeias, mas nós desejamos que ela possua uma visão alargada e descentrada, o que quer dizer concretamente que muitas línguas possam se exprimir, bem como articular diversas aproximações metodológicas. Se a associação ganhou corpo tão rapidamente foi porque os pesquisadores nela encontraram exatamente um lugar de expressões múltiplas. As visadas são muito diversificadas e não se concentram essencialmente sobre os Performance Studies, como é o caso de inúmeros departamentos acadêmicos.

Há alguma diferença fundamental entre os Performance Studies e a visão da EASTAP?

O âmbito dos Performance Studies é tão vasto, tão amplo que tudo pode neles caber. Tudo é performance. É exatamente o que afirma Richard Schechner. O aspecto estético do teatro foi perdido; enquanto a tradição europeia permanece fundada sobre a análise estética, a dramaturgia e a história. São esses enfoques que a EASTAP quer colocar em primeiro lugar, sem discriminação.

\section{A Associação tem interesse, nesse momento, em se abrir para outros continentes, como as Américas, a Ásia, a África? Como a Associação vê essa questão de agregar novos pesquisadores?}

Os pesquisadores não europeus são, evidentemente, muito bem vindos na Associação. Embora ela seja "europeia”, isso não implica ser apenas para aqueles que moram na Europa, mas a todos que pesquisem sobre o teatro europeu, ainda 
mais quando essa noção possa ser alargada sobre as influências fora da Europa. Nós temos no momento 360 membros, vindos de 42 países e nem todos são europeus. Há gente do Japão, do Egito, do Brasil, da Nova Zelândia, da Austrália... Nós estamos muito felizes com essa diversidade. E desejamos mesmo que não haja uma preponderância de integrantes anglo-saxões, embora a língua dominante seja o inglês. Se uma língua domina, traz com ela uma dominação de enfoques críticos anglo-saxões. Quando nós desejamos promover uma abertura e um outro equilíbrio. O objetivo é trabalhar, na medida do possível, com temáticas europeias ou visadas sob um ângulo anglo europeu.

\section{Temáticas europeias?}

Nossos temas orbitam em torno da memória (em Lisboa), sobre a composição cênica (Bolonha, 2020). São assuntos universais, mas percebidos em um contexto europeu.

Me parece que há uma curiosidade, por um lado, e uma necessidade, por outro, de se fazer esse tipo de pesquisa. Mas eu tenho uma questão relativa à concepção do performativo, termo que você difundiu e promoveu em muitos textos, enfoques renovados e tudo isso. Qual é, nesse momento, a acepção de performativo para você.

A noção de "teatro performativo" é uma noção que me afeta particularmente e que parece dar conta das práticas empregadas hoje em dia bem mais que outras expressões dominantes, notadamente aquela de pós-dramático utilizada por Hans-Thies Lehmann. Se voltarmos às origens, o que exatamente quer dizer performativo? A palavra performativo vem da linguística e exprime, em Austin, "os verbos que acompanham as ações". Nessa acepção, o teatro performa hoje em dia, ele acompanha as ações e força os espectadores a acompanha-las. Isso quer dizer que o teatro não está mais na representação, na interpretação, na mimesis (mesmo quando existam cenas onde a mimesis está em jogo), mas na performance, na presença, no acontecimento, e até mesmo no real. O espectador 
é convocado a experimentar. E essa experiência está no coração do processo cênico. Os espetáculos do Rimini Protokol ou aqueles da Blast Theory colocam o espectador no centro. Ele está no coração do processo de criação. Sem ele, o espetáculo não existe. É nesse sentido que eu penso que o teatro atual se tornou cada vez mais performativo. É o caso dos espetáculos de Milo Rau, de Thiago Rodriguez ou de Antônio Araújo. São artistas dos quais eu me sinto próxima, porque eles falam de uma sensibilidade de hoje. É a mesma de Wajdi Mouawad, na qual os espetáculos atravessam várias fronteiras (linguísticas, ficcionais, temporais, espaciais) e deslocam o espectador.

\section{Nesse momento, quais suas impressões sobre as mudanças no panorama cênico mais amplo? Há alguma tendência artística dominante que a interesse particularmente?}

É difícil não citar alguns nomes. Tudo depende do lugar de onde se fala. Por exemplo, há uns dez anos, quando eu voltei para a França para dar aulas na Sorbonne-Nouvelle, eu lancei um curso sobre o teatro flamengo, um teatro que renovou a paisagem teatral e que era muito pouco conhecido. Hoje em dia, esse teatro está em todos os lugares e todo mundo conhece, como STAN (acrônimo de Stop Thinking About Names), Yvo van Hove, Guy Cassiers, Jan Lauwers, Alain Plantel, a companhia BERLIN... Se você me perguntar quais são os encenadores atuais interessantes, eu diria que são todos esses que citei. Os flamengos ainda permanecem muito interessantes. Mas também encenadores como Brett Bailey, da África do Sul ou Simon Stone, da Austrália, são igualmente curiosos e notáveis. Eu sempre adoro o que fazem Ostermeier e Kentridge. Ainda poderia citar Shermin Langhoff, She She Pop, Lola Arias... Entre os mais jovens, Julien Gosselin e Thomas Jolly são muito cativantes. É difícil nomear apenas alguns. Eu gostaria de nomear todos. E há ainda Angélica Liddell, uma artista que, mesmo se eu não considere apaixonante tudo o que ela faz, há sempre sua inventividade, sua criatividade, sua fúria, que são deslumbrantes. 
O que mais especificamente atrai sua atenção no teatro flamengo? O texto, os atores, os encenadores?

Esse teatro possui sempre atores notáveis. As Tragédias Romanas e Reis da Guerra, de Ivo van Hove, foram realizações memoráveis, grandes momentos cênicos. É um teatro onde o ator está no centro, um ator que não depende do texto mas que o reinventa com muito poder. A fórmula é banal, mas aqui possui toda sua força. Se você me perguntasse o que eu amo em seu teatro, eu diria que é essa liberdade, esse estar distante de uma tradição poderosa ou de uma teatralidade convencional. Ele reinventa as coisas, adapta clássicos e modernos com uma maestria invejável. É um teatro que não é arrogante e que faz a gente amar o teatro. Onde ninguém se entedia jamais.

Após tantas reviravoltas da cena nas últimas décadas, o que sobra, para você, do charme do teatro, o que a tira de casa para entrar numa sala de espetáculos?

O encontro de um ator em cena e de um espectador é qualquer coisa única. Não há nenhum outro local do mundo que permita esse entreolhar. É um encontro extraordinário e sempre renovado àquele que é instigado. Nosso imaginário, nossa inteligência, nossa sensibilidade são solicitados todos de uma vez. Quanto à teatralidade, ela se revela de modos variados. Ela vai e vem. Nós estamos sempre condenados à procura-la, e mesmo à inventa-la.

Em sua opinião, esse retorno da teatralidade é uma revanche cênica contra a crescente dispersão provocada pelas mídias digitais?

A imagem digital solicita o espectador de outro modo e a atenção que ela demanda pode ser fatiada e flutuante. Não é o caso do teatro, que exige um modo de atenção mais embaraçoso, se ouso dizer, que se inscreve na duração, mesmo quando as estéticas atuais reproduzem o fracionamento das mídias. Cada vez mais a tela - ou as telas - constituem as interfaces que afastam o sujeito do real, 
enquanto o teatro reaproxima paradoxalmente o espectador do real. Nós somos o mesmo intermediário.

O que há de novo em termos de teoria teatral na Europa? O que se discute? Quais as novas perspectivas de análise empregadas pelos jovens pesquisadores?

A teoria teatral não conhece grandes revoluções há algum tempo. A invenção dos Performance Studies, há 50 anos, é que provocaram uma mudança maior em nossa disciplina. A noção de pós-dramático foi igualmente importante, desde há 25 anos até o presente, mesmo que eu continue a considera-la uma expressão pouco feliz. É bastante tempo, portanto, para que outra mudança teórica seduza aqueles responsáveis pela evolução do teatro atual, que se encontra muito desestruturado, muito mais relacional (como diz Bourriaud) que em outras épocas. Eu preconizo então a noção de teatro performativo hoje em dia, para ficar em sintonia com aquilo que se faz.

Tradução de Edélcio Mostaço.

Agradeço a Jeremie Bonheure pela transcrição da fita em francês.

Recebido em: 27/08/2020

Aprovado em: 27/08/2020 